\title{
https://doi.org/10.48009/2_iis_2009_520-528 \\ IDENTITY THEFT RECOVERY: USING EQUITY THEORY TO EXPLORE THE NEED FOR VICTIM ADVOCACY
}

\author{
Paul Visentin, Appalachian State University, paul.m.visentin@gmail.com \\ Scott Hunsinger, Appalachian State University, hunsingerds@appstate.edu \\ Dawn Medlin, Appalachian State University, medlinbd@appstate.edu
}

\begin{abstract}
Identity theft is one of the fastest growing crimes in the United States. After victimization, there is a high price for the victim to pay in both effort and money, while the perpetrator of the crime often receives high compensation from the crime. According to equity theory, if an individual judges the output of a relationship to be unequal to a related relationship, the individual becomes increasingly distressed. Equity theory has been applied in previous IS research to examine areas such as users' satisfaction and software piracy. In the case of identity theft, we see a relationship between the victim and society being compared to the relationship between the perpetrator and society. Our study seeks to capture both quantitative and qualitative data through a case study of a victim to explore the effects of the perceived inequity by the victim and its effect on their productivity. Further, this study suggests future research for exploring the cost benefit of offering subsidized advocacy in the workplace.
\end{abstract}

Keywords: Identity Theft, Equity Theory, Recovery, Advocacy

\section{INTRODUCTION}

Identity theft is an increasingly difficult crime for victims to detect. One study showed that $25 \%$ of victims did not discover the crime for two or more years after it occurred [5]. Even more disturbing is the average amount of time it takes to clear the victim's name. The average time spent to rectify problems caused by an identity theft is 97 hours for victims where an existing account was the target, and 231 hours in cases where a new account was created [5].

In previous surveys and studies on identity theft, the focus has been geared towards the financial costs to the victim. A handful of studies go so far as to address the psychological costs to the victim, confirming that victimization has the potential to drastically reduce productivity. Dr. Charles Nelson

Volume X, No. 2, 2009 describes the psychological state of many identity theft victims as following the classical symptoms of

post traumatic stress disorder [5]. In a report prepared by the Federal Trade Commission, according to 38\% of respondents, the number one challenge faced by victims was the dispute resolution process. Of those who responded, $26 \%$ cited the emotional impact as the biggest challenge faced during the resolution process. In 2006 alone, there were an estimated 8.3 million adult victims in the United States suffering through struggles to regain their identity and financial security [20].

The government's response to the increase in identity theft has been to raise the criminal classification of the crime, adding jail time and larger fines at the federal level. At the state level, similar increases in criminalization have taken precedent over creating a uniform recovery process for the victims. Many victims are finding that they cannot file a local police report of the crime, which is a key document to the recovery of financial damages [16].

The purpose of this study is to explore the recovery process through the eyes of an actual victim and to apply equity theory to examine the victim's perceived level of fairness in the treatment they received. Through exploring the level of perceived fairness by one victim, we will provide the justification for future study applying equity theory, and also establish the need for greater advocacy for victims. We will do this by first conducting a literature review, including recent data submitted by key advocacy groups and the Federal Trade Commission. In order to make the case for applying equity theory, we will review studies in other domains that have used equity theory to model the victim/victimizer relationship. We will also review other areas in Information Systems in which equity theory has been applied, including user satisfaction and software piracy. We then use an interview protocol to examine the financial, time, and emotional costs incurred by a victim and the perceived fairness of the treatment they received. We apply the information from our study and our literature review to draw conclusions as to the 
viability of applying equity theory in this domain and suggest ideas for future research.

\section{LITERATURE REVIEW}

\section{Overview of Identity Theft}

The scope of how identity theft can be perpetrated on a victim is large. The level of theft can range from the takeover or creation of bank accounts, credit cards, loans and/or utility services, to gaining employment and even using the victim's identification during the commission of other crimes [5]. The Federal Trade Commission, the leading government agency charged with tracking identity theft, estimates 3.7 percent of American adults (8.3 million) were victims of some form of identity theft in 2005 [20]. Of the 8.3 million adults, 1.8 million had new accounts created in their name by criminals, 3.3 million experienced fraud using existing noncredit card accounts, and 3.2 million encountered theft with existing credit-cards [20]. In cases where an existing account was overtaken, the Identity Theft Resource Center reports that it takes almost 100 hours on average to clear the fraud, at an average cost of $\$ 1,884$ to the victim. It took an average of 231 hours and $\$ 1,342$ for the victim to clear the fraud involving a new account [5]. New account fraud is considered the fastest growing form of identity theft [4]. The costs incurred include postage, photocopying, travel, childcare, record request fees, and attorney fees related to the recovery of financial identity [5].

A more recent study (The Javelin 2007 Identity Fraud Survey Report) states that it takes an average of 55 hours to repair damage at a cost of $\$ 5,270$ to the victim [17]. Despite the range in the reported figures, these studies suggest that the physical costs to a victim are quite high.

The number of real hours spent recovering from identity theft is highly variable and lengthy, just as the time frame in which those hours are spent. It takes at least a year for 59\% of victims to recover and it takes over two years for another $27 \%$ to recover [5]. In general, the timeframe in which the victim has the opportunity to make the phone calls and travel to clear their name is not during the weekend or in the evening, but during the normal work week [2]. This creates a loss in employee productivity for victims, which affects the bottom line of a business [2]. Businesses are already taking a large hit to their profit due to risk management from being sources of stolen information [7], and from the estimated $\$ 52.6$ billion cost of US fraud per year [17].

\section{Secondary Wounding and Emotional Toll}

While the financial and time costs of being a victim of identity theft are somewhat concrete, there are other effects known as secondary wounding. When asked, $30 \%$ of respondents stated, "my ability to go on with my life is still being impacted" well over two years from the discovery of identity theft, and $7 \%$ stated that they were still affected ten or more years later. These secondary wounding effects include credit denial, increased rates on insurance and credit, collection harassment, card cancellations, inability to get employment and credit, and an inability to clear a false criminal record. The most common effects were difficulties gaining credit and loans (63\%), credit denial $(51 \%)$, and collection agency harassment $(46 \%)[5]$.

The emotional costs after the original crime are not taken into account when dealing with secondary wounding, but they should be considered when accounting for a loss in productivity [2]. Dr. Nelson, a noted victim psychologist, provides a section in the Identity Theft Resource Center (ITRC) Aftermath Report that sheds light on the extreme toll taken on victims as evident in the following quote:

"This study clearly proves the impact of identity theft on its victims leaves similar scars and long-term impact as demonstrated by victims of violent crime....It is disturbing to see how many people felt exhausted, too tired to continue to fight or even consider suicide instead of standing up for their rights..." [5].

The ITRC report includes a large table of emotional responses/symptoms describing a experience. Twenty-eight percent (28\%) of respondents stated that they felt shame, and $29 \%$ felt an inability to trust others [5]. The Federal Trade Commission reported that $26 \%$ of respondents stated that the biggest challenge they faced was the emotional toll [20].

\section{Recovery}

The process of recovering from identity theft is unclear and varies depending on the source. According to the FTC identity theft survey, the biggest challenge faced by victims of identity theft is going through the recovery process [20]. The 
consumer advocacy group Fight Identity Theft outlines a seven step process that it advises victims to go through. These steps are set up into two subsections; one subsection is set up to research the loss, and the other is recovery based [18].

The federal government has provided several conflicting documents with instruction for recovery coming from various agencies. The FTC recommends a four step process which covers both research and recovery [9]. The Office of the Attorney General suggests a five step plan which is primarily recovery based [13]. The overall steps in each process are the same, but their explanations state that one step in the process requires the previous steps to be completed. This problem is most often found when trying to file a police report. According to the ITRC report, many victims struggle to find the right documentation to bring, or even to have the police hear their claims at all [5]. Table 1 illustrates inconsistencies between agencies in their outlines to recovery.

Table 1. A Comparison of Recovery Steps

\begin{tabular}{|l|l|l|l|}
\hline Fight Identity & FTC & $\begin{array}{l}\text { Office of the } \\
\text { Attorney } \\
\text { General }\end{array}$ \\
\hline $\begin{array}{l}\text { Step } \\
\text { One }\end{array}$ & $\begin{array}{l}\text { Research } \\
\text { credit records }\end{array}$ & $\begin{array}{l}\text { Place fraud } \\
\text { alert }\end{array}$ & $\begin{array}{l}\text { File police } \\
\text { report }\end{array}$ \\
\hline $\begin{array}{l}\text { Step } \\
\text { Two }\end{array}$ & $\begin{array}{l}\text { Place fraud } \\
\text { alert }\end{array}$ & $\begin{array}{l}\text { Close } \\
\text { accounts }\end{array}$ & $\begin{array}{l}\text { Close } \\
\text { accounts }\end{array}$ \\
\hline $\begin{array}{l}\text { Step } \\
\text { Three }\end{array}$ & $\begin{array}{l}\text { Research } \\
\text { location of } \\
\text { fraud }\end{array}$ & $\begin{array}{l}\text { File police } \\
\text { report }\end{array}$ & $\begin{array}{l}\text { Place fraud } \\
\text { alert }\end{array}$ \\
\hline $\begin{array}{l}\text { Step } \\
\text { Four }\end{array}$ & $\begin{array}{l}\text { File police } \\
\text { report }\end{array}$ & $\begin{array}{l}\text { File FTC } \\
\text { complaint }\end{array}$ & $\begin{array}{l}\text { Research } \\
\text { credit } \\
\text { records }\end{array}$ \\
\hline $\begin{array}{l}\text { Step } \\
\text { Five }\end{array}$ & $\begin{array}{l}\text { Clear fraud } \\
\text { with creditors }\end{array}$ & - & $\begin{array}{l}\text { File FTC } \\
\text { complaint }\end{array}$ \\
\hline $\begin{array}{l}\text { Step } \\
\text { Six }\end{array}$ & $\begin{array}{l}\text { File FTC } \\
\text { complaint }\end{array}$ & - & - \\
\hline $\begin{array}{l}\text { Step } \\
\text { Seven }\end{array}$ & $\begin{array}{l}\text { Continued } \\
\text { monitoring of } \\
\text { credit }\end{array}$ & - & - \\
\hline
\end{tabular}

\section{Modern Victim Advocacy}

Currently there is a very limited set of options for a person looking for a victim's advocate when dealing with their own identity theft. Insurance agencies offer small rider packages to homeowners insurance to aid in recovery, averaging \$25-100 per month [10]. Jaffe [10] believes the price is reasonable, but gives inadequate coverage. In his article outlining the services offered, Jaffe found that, "...the typical policy provides $\$ 15,000$ to $\$ 25,000$ worth of coverage...for expenses, phone bills, lost wages, notary and certified mailing costs, and sometimes attorney fees with prior consent from the insurer..." [10]. Jaffe goes on to explain how this coverage is inadequate:

"Some policies do not cover lost wages due to time away for work, or provide only a minimal payment for that time... Coverage for attorney's fees must be preapproved, and some consumers have reported that trying to collect on the insurance amounted to an additional hassle on a situation that is already a great pain" [10].

Not all policies are inadequate, as Liberty Mutual offers coverage that includes advocacy from credit counselors who walk victims through the process, some even going so far as to take care of mailings and calling creditors on behalf of the victim [10]. While particular care must be taken if a person does decide to get insured on their own, it does not offer victims help who did not foresee the need for purchasing it.

There are post victimization services such as Identity Theft 911, which is being offered as a component of some insurance plans and has been offered as an enterprise solution [15]. Identity Theft 911 assigns an individual agent to the victim to place fraud alerts, fill out affidavits and police reports, and navigate the legal system [15]. The American National Property and Casualty Companies, one organization offering Identity Theft 911 as an insurance benefit, has estimated that a victim can expect to lose over 20 days of work restoring their identity, which has justified their use of the program [15]. Sheryl Christenson, CEO of Identity Theft 911, states that their service is unique compared to other insurance options in that the one on one service is offered [2].

\section{Equity Theory}

Introduced in 1965 by J. Stacy Adams, equity theory was created as a general theory to support other social interaction theories which were not accounting for a qualitative reason behind social interactions. Equity theory is based upon the idea that people are motivated not only by strict self interest, but to establish or restore equity. When modeling equity theory, the comparison is between the inputs over outputs of one subject compared to a related subject's inputs over output [14]. The theory has been heavily applied to motivation and productivity in the 
workplace, and has also been used to explain victim/exploiter relationships.

Equity theory has also been applied in several areas in IS research. Joshi [11] used equity theory as a foundation to develop an instrument to measure fairness or equity in the context of MIS. In a followup study, Joshi [12] applied equity theory to the allocation of IS resources. Joshi [12] proposed that perceived inequity in the allocation of these resources likely influences overall user information satisfaction. Glass and Wood [6] used an equity theory perspective to predict the influence of situational factors on a person's intention to pirate software.

The theory proposes that "when individuals find themselves participating in inequitable relationships, they will become distressed. The more inequitable the relationship, the more distress individuals will feel" [3]. In Figure 1, the ideal state of interpersonal equity is depicted where no feelings of inequity are felt [6].

$$
\frac{\text { Outputs [A] }}{\text { Inputs [A] }}=\frac{\text { Outputs [B] }}{\text { Inputs [B] }}
$$

Figure 1. Ideal state of equity - Basic Equity Theory

To further illustrate this concept, consider two employees with similar demographical backgrounds assigned to work on a task. Employee A perceives that he/she has put forth one hundred hours of quality effort into the project (Inputs [A]). Employee A observes that Employee B has completed seventy five quality hours of work (Inputs [B]). When the task is completed, the supervisor extends praise to Employee B for his/her hard work (Outputs [B]), but no praise is given to Employee A (Outputs [A]). In this simplified scenario, Employee A would feel distressed at his/her perceived state of unequal treatment. There is also a chance in this scenario in which Employee B would feel distressed over the inequity as guilt.

Equity theory has been criticized as oversimplifying the relationship of equity. To improve upon this, an additional equity sensitivity construct was proposed. Based upon previous psychology research, the equity sensitivity construct created three different personality types based on how they would become distressed by inequity. The first group, Benevolents, become distressed when they feel as though they are being over-rewarded for their efforts. Benevolents, in fact, find satisfaction in putting in high levels of input and do not require outputs for satisfaction. Figure 2 illustrates the relationship for Benevolents.

$$
\frac{\text { Outputs [A] }}{\text { Inputs [A] }}<\frac{\text { Outputs [B] }}{\text { Inputs [B] }}
$$

Figure 2. Relationship for "Benevolents"

The second group, Equity Sensitives, is represented in the traditional equity theory shown in Figure 3.

$$
\frac{\text { Outputs }[\mathrm{A}]}{\text { Inputs }[\mathrm{A}]}=\frac{\text { Outputs [B] }}{\text { Inputs [B] }}
$$

Figure 3. Relationship for "Equity Sensitives"

Entitleds, the third and final group, represents the opposite of the Benevolents. The Entitleds feel distressed when they perceive themselves to have been under-rewarded and entitled to a better situation than other individuals that they might compare themselves with. Each of these equity groups are depicted in their state of preferred equity in Figure 4 [8].

$\frac{\text { Outputs [A] }}{\text { Inputs [A] }}>\quad \frac{\text { Outputs [B] }}{\text { Inputs [B] }}$

Figure 4. Relationship for "Entitleds"

In a study on violent crime victims, a strong relationship was found between the victim's satisfaction with the criminal justice system and the punishment of the criminal and any damages awarded to the victim [1]. This study found that, in order to reduce the victim's feelings of inequality, one of two things had to occur. Either the outcome that the victim receives must be increased, or the outcome to the criminal must be reduced. Amick-McMullan et al. [1] theorizes that the victim's outcome can be increased by "treating them well and by providing them with services", and the criminal outcome can be reduced by "direct retaliation by the victim or timely action punishment from the criminal justice system." This perception of fairness is based on the victim's view of the criminal justice system as an agent of equity. Given the similarities in psychological symptoms between identity theft victims and victims 
of violent crimes [5], the Amick-McMullan study [1] lays the groundwork to apply equity theory to victims of identity theft.

\section{METHODOLOGY}

First, we analyzed our literature review to construct an outline for a structured interview that would allow flexibility for follow up questions at the end of the protocol. The primary purpose of the protocol was to conduct a detailed study of an actual instance of identity theft. The secondary purpose of the protocol was to compare the victim's statistics to the statistics reported in the literature review. Using the responses from the protocol, we were able to plug in concrete actions and numbers to the equity theory equations from the literature review.

The following questions relate directly to the application of equity theory:

I. What does the victim identify as their inputs to the process of having their identity stolen and the subsequent recovery?

II. What does the victim identify as the outcomes after having their identity stolen and going through the recovery process?

III. What does the victim identify that the perpetrator put into stealing their identity?

IV. What does the victim identify that the perpetrator received out of stealing their identity?

V. Does the victim feel equitably treated by society and why?

We began our research by searching for a potential interviewee who matched our basic criteria; that they had been a victim of financial identity theft. We found a person who met the criteria, and he agreed to participate in our study.

In our pre-interview contact, we asked for permission to conduct a structured interview with some followup questions. In addition, permission was acquired in order to record the conversation. It was made clear that the subject had the option to skip any question that he did not feel comfortable with. After the subject agreed to participate, we conducted a phone interview, asking a total of 37 questions. Once completed, we transcribed the recording of the interview to verify the short hand notes that had been taken during the conversation. (The protocol and transcribed interview are available by request. All identifying information has been removed to protect the confidentiality of the subject.)

\section{FINDINGS}

We asked a series of questions to reveal data about the quantitative loss due to the subject's victimization. The subject experienced financial identity theft, where several accounts were used to charge a total of $\$ 15,000$ worth of goods across two credit cards and a debit card. We found that the individual spent an estimated 150 hours to regain his identity. While all of his financial losses have since been recovered due to his credit card company's efforts, there are still effects seen on his credit report four years after the initial breach.

We compared these costs to the average values regarding existing account fraud from the Federal Trade Commission (FTC) and Identity Theft Resource Center as shown in Table 2. The FTC did not collect average costs, but the median and $90^{\text {th }}$ percentile of costs. In Table 2, both of these values are shown where applicable and the $90^{\text {th }}$ percentile value is designated with an asterisk. The ITRC did not collect an average victim loss.

Table 2. Comparison of case losses to average losses

\begin{tabular}{|l|l|l|l|}
\hline \multicolumn{1}{|c|}{ Cost } & \multicolumn{1}{|c|}{$\begin{array}{c}\text { Case } \\
\text { Subject }\end{array}$} & $\begin{array}{c}\text { FTC } \\
\text { Median / } \\
\mathbf{9 0}^{\text {th }} \\
\text { percentile* }^{*}\end{array}$ & \multicolumn{1}{|c|}{$\begin{array}{l}\text { ITRC } \\
\text { Average }\end{array}$} \\
\hline Loss & $\$ 15,000$ & $\begin{array}{l}\$ 350 \\
4,000^{*}\end{array}$ & N/A \\
\hline $\begin{array}{l}\text { Out of pocket } \\
\text { expense }\end{array}$ & $\$ 0$ & $\$ 0 / \$ 132^{*}$ & $\$ 1,884$ \\
\hline $\begin{array}{l}\text { Timeframe } \\
\text { of } \\
\text { involvement }\end{array}$ & 4 years & 1 month & 1 year \\
\hline Real hours & 150 & $0 / 25^{*}$ & 97 \\
\hline
\end{tabular}

In addition to the quantitative data gathered during the structured sections of the interview, several open ended questions revealed a great deal about the subject's experience and emotional effects of being a victim. The following subsections explain this qualitative data in more detail. 


\section{Breach and Notification}

The thief in this case gained access to the victim's identity trough a Trojan horse program that was installed on the subject's computer. The thief made several purchases of electronic equipment and had it delivered to Texas. In the beginning stages of the fraud, the purchases were too small to raise any flags with the bank or credit card companies. When attempting to make a debit card purchase, however, the victim was notified that he had insufficient funds. Shortly after calling the issuing bank, the subject received a call from the credit card issuer's fraud department, informing him of potential fraudulent charges. The company suspected fraudulent behavior when a large amount of electronics were purchased and shipped to a Texas addressee, while at the same time, a charge from the same address was to have the electronics was to be delivered to Africa. The subject stated, "There is definitely a shock and awe feature with that situation..." when asked about how he felt when he found out.

\section{Advocacy and Recovery}

During the recovery process, the subject had received a negative reaction from several of the entities that he had dealt with while attempting to resolve his initial fraud problem. When filing a police report with the county sheriff's department, he felt that they were "not at all helpful," and that after he went through the motions of filing the police report, he "never heard anything after that." Similarly, when dealing with the three main credit reporting bureaus (Equifax, Experian and TransUnion), the victim stated that they were "not real helpful," as the customer service he dealt with was outsourced. When asked why he felt that way, he replied: "You questioned whether or not you should give your social security number to the people you were talking to. You become very pessimistic in believing that the people you were talking to were also going to take your identity. It's not a good feeling."

While the subject did have some negative responses to his treatment from a few organizations, he had an overwhelmingly positive reaction to how he was treated by his credit card company. He stated, "they took care of everything including the legal costs and everything else to remedy not only their card, but the other credit card and my checking accounts." The most telling statement the subject made regarding his credit card company was made after he was asked how fair he felt treated: "I've got to tell you; the reason we've stuck with [the company] has been the absolute professional way and proactive approach they used to identify the problem and taking care of the problem without my pushing to make it happen. They did a fantastic job."

\section{Aftermath}

The subject has regained the stolen money and has had all of his financial costs including legal fees, notary fees, and postage etc., associated with regaining his financial identity covered by his credit card company. Despite these successes, he still sees negative consequences from being a victim. There are several addresses still tied in with his social security number and name within his credit reports, as the credit agencies refuse to remove them. As an added safeguard, he has placed credit alerts and a requirement for verification if a large amount of money is requested. Unable to put a quantitative value on what he felt his lost productivity was, he said "It negatively affects you. It affects you because it absorbs your mind to the point where you really do lose your productivity because your focus is something else."

When asked about the most frustrating thing related to the entire experience, he stated, "the leg work of having to contact the different credit agencies and going through getting on the credit watch lists and finding the websites and that type of thing; At the time, none of that was real, it was something that was happening, but there was not a lot of real clear concise information, there was a lot of crap on websites and stuff that really didn't lead you to where you wanted to go."

To this date, the victim has no idea who the thief actually is or if they were ever caught. The extent of his knowledge of the investigation ceased when the trail moved international and he was told that "not often did they get these people internationally and then end up having legal prosecution on them." $\mathrm{He}$ then theorized that it was cheaper for the company to write off his loss than to actually go after the individual. It is also interesting to note that the subject was asked multiple times if he felt treated fairly throughout the entire situation. Each time he responded that he felt fairly treated saying "I wasn't treated poorly. I think I just had the same thing that everybody who goes through that process feels the frustration of not knowing what the next step is." 


\section{DISCUSSION / EQUITY THEORY APPLICATION}

The number of identity theft victims has been increasing over the past decade. The approach society has taken to protect consumers has been mostly proactive, while increasing the reactive approach for the perpetrators. Though the approaches appear to be good ones, it does leave the reconstructive effort for the victim unsupported. After interviewing the victim about his experiences and his attempts at recovering from identity theft, the researchers were able to acquire a more realistic picture into the struggles and triumphs of a person who has had their identity stolen.

It is apparent that the details of the subject's experience only partially match up with those sampled and surveyed throughout the FTC, ITRC reports, and other horror stories seen throughout the media. Keeping that in mind, we still see the disturbing similarities that put large hours of phone calls, unhelpful police and credit bureaus up against a single consumer who is unsure where to turn first.

To apply equity theory to this case, we can see that a subject that spends roughly 150 hours to fully recover $\$ 15,000$ in damages in comparison to that of the thief is truly an imbalanced equation. The thief in question potentially put in very little time to deploy and maintain the Trojan to receive the $\$ 15,000$. These values, which were the answers to questions $\mathrm{I}-\mathrm{V}$ in the methodology, have been applied below in Figure 5 according to the basic equity theory equation.

\begin{tabular}{ll}
\multicolumn{1}{c}{ Victim } & \multicolumn{1}{c}{ Perpetrator } \\
Net Gain $\$ 0$ & Net Gain $\$ 15,000$ \\
\hline 150 Hours & $\begin{array}{l}\text { Cost of Trojan } \\
\text { development + time to } \\
\text { coordinate shipping }\end{array}$
\end{tabular}

Figure 5. Equity theory applied to case study results

Given the equation in Figure 5, one would assume that the victim would feel distressed because the equity is overwhelmingly in the favor of the perpetrator who received a large benefit after putting in very few inputs. The victim in this case put forth a large amount of inputs and struggled to break even regarding the outputs received. Given the assumption based on the equation, it was surprising to see that it did not match up with the victim's response when asked if he felt like he had been fairly treated. This indicates that a very basic assumption that has been made previously about how victims perceive equity in identity theft cases may need to be revised.

For this individual, who was able to recover all losses and expenses, this puts the subject in a frame of mind that may be deemed unfair by other victims who did not receive the same amount of advocacy. The overall satisfaction of this subject and the fairness perceived can be directly attributed to the advocacy that the credit card company offered and results they achieved.

\section{SUGGESTIONS FOR FUTURE STUDY}

The story could have been vastly different if the subject's credit card company had not been as helpful. The idea that not all victims receive the same type of service is paramount to demonstrating the need for future research in this domain. More subjects should be included in a further study in order to gain a better cross section of the experiences held by the victims of identity theft. The lack of a larger sample is the largest weakness of this study; however, it remains appropriate as a foundation for future research.

The protocol used in this study worked for an individual interview, but should be modified in order to distribute to a larger audience. A survey would be more useful for a study of larger scope. In this study, we discovered that not all victims will compare their inputs and outputs to those of the perpetrator. Further protocols should also investigate who victims compare themselves to for the purposes of equity. One possible explanation for the victim in this case not comparing themselves to the perpetrator may be due to the anonymity of that individual's identity. Future study should identify if people that compare their treatment to that of the perpetrator have knowledge of who the perpetrator actually is. The possibility exists that the perpetrator may not be a factor at all and that equity is evaluated in relationship to fellow victims.

Once this next phase in research is complete, the focus can be shifted away from the victims and towards potential societal agents of reconciliation. If there is a perceived inequity felt by victims going through the identity theft recovery process, then ways to restore equity should be researched. This activity can be conducted through a general survey of credit 
issuers and what they offer their credit holders in terms of recovery. Given that some credit issuers are able to offer complete recovery, the inconsistency in the industry should be investigated as to how widespread the discrepancies are and their solutions.

Other possibilities for the provision of identity theft recovery could be researched, including an analysis of offering direct advocacy as an employment benefit. With the dramatic psychological effects reported across the FTC and ITRC reports it is highly probable, yet currently undocumented, that becoming a victim of identity theft will have an effect on productivity in the work place. If the effects of identity theft are going to ripple into the workplace then the workplace may be a suitable option to offer an advocacy service to its employees either through insurance or preferred card memberships.

\section{CONCLUSION}

Identity theft remains a growing problem that leaves a path of devastation through the emotional and financial life of its victims. In an instance where advocacy was highly prevalent in the victim's recovery effort, it was easy to see a decrease in the amount of stress felt by the victim. Secondary research shows that this type of advocacy could be considered the exception to the rule. According to equity theory, a victim not receiving a high level of advocacy would feel an increase in their distress when comparing themselves to a victim who is receiving an increased level of advocacy. This increase in stress added to an already stressful situation. It is important that steps are taken to find new ways so that each victim would receive similar level of advocacy. While different credit card issuers struggle to provide uniform experiences during recovery, the workplace may serve as a platform to offer quality victim advocacy as a benefit. For future study, a cost benefit analysis could be performed to see if an increase in a victim's work productivity outweighs the cost of a business providing advocacy training as a benefit.

\section{REFERENCES}

1. Amick-McMullan, A., Kilpatrick, D., Veronen, L. and Smith, S. (1988). Family Survivors of Homicide Victims: Theoretical Perspectives and an Exploratory Study. Journal of Traumatic Stress, 2(1) 21-35.
2. Anonymous. (2008). Identity Theft: Helping Employees Find Themselves. Risk Management, 55(3) 12.

3. CTER. (2006). Equity Theory. WikEd, Curriculum, Technology, \& Education Reform. http://wik.ed.uiuc.edu/index.php/Equity_Theory.

4. FDIC. (2004). Putting an End to Account Hijacking Identity Theft. FDIC: Washington D.C.

5. Foley, L., Gordon, S., Barney, K., Rice, K., and Nelson, C. (2006). Identity Theft: The Aftermath 2006, Identity Theft Resource Center: San Diego, CA.

6. Glass, R. and Wood, W. (1996). Situational determinants of software piracy: An equity theory perspective. Journal of Business Ethics. 15(11), 1189-1198.

7. Gordon, G., Rebovich, D., Choo, K., and Gordon, J., (2007). Identity Fraud Trends and Patterns: Build a Data-Based Foundation for Proactive Enforcement. Center for Identity Management and Information Protection: Utica, NY.

8. Huseman, R., Hatfield, J., and Miles, E., (1987). A New Prerspective on Equity Theory: The Equity Sensitivity Construcy. Academy of Management Review 12 (2), 222-234.

9. InfoFAQ (2007). How to Take Appropriate Steps to Theft Recovery, Infofaq http://www.infofaq.com/fraud/credit-card/stepsrecovery.html.

10. Jaffe, C. (2006). Stupid Investment of the Week: Identity-Theft Insurance isn't Even Worth it's Small Price, MarketWatch, Boston, MA.

11. Joshi, K. (1989). The Measurement of Fairness or Equity Perceptions of Management Information Systems Users. MIS Quarterly 13 (3), 229-242.

12. Joshi, K. (1990). An Investigation into Equity as a Determinant of User Information Satisfaction. Decision Sciences 21 (4), 786-807. 
13. King, G. (2007). Identity Theft Prevention and Repair Kit. New Mexico Office of the Attorney General: Santa Fe, NM.

14. Know, J. (2003). Which is the Fairest One of All: A Positive Analysis of Justice Theories. Journal of Economic Literature, 43 (December 2003), 1188-1239

15. Martin, S. and Wert, J. (2006). ANPAC Provides Advocacy for Victims of Identity Theft, Bliss, Gouverneur \& Assoc.: Springfield, MO.

16. Matejkovic, J., and Lahey, K. (2001). Identity Theft: No Help for Consumers. Financial Services Review, 10 (1-4) 221-235.

17. Monahan, M., (2007). Identity Fraud Survey Report: Identity Fraud is Dropping, Constant Vigilance Necessary. Javelin Research: Pleasanton, CA.

18. Nielson, D. (2009). Identity Theft Recovery Guidelines. Fight Identity Theft! http://www.fightidentitytheft.com/print/identity_ theft victim.html.

19. Phan, D. (2005). Identity Theft Survey 2005, Better Business Bureau/Javelin Research: Pleasanton, CA.

20. Synovate. (2007). Federal Trade Commission 2006 Identity Theft Survey Report, Synovate: McLean, VA. 